\title{
Search by Clinical Methods for Persistent Urinary Infections in Children
}

\author{
P. M. DUNN,* M.A., M.B., B.CHIR., D.C.H., D.OBST.R.C.o.G. ; L. C. HINE, † F.I.M.L.T. \\ M. E. MACGREGOR, $\ddagger$ M.D., F.R.C.P.
}

Brit. med. F., 1964, 1, 1081-1084

There is general agreement that persistent infection of the urinary tract is a common disease in infancy and childhood, and that, if it is not checked-whether its clinical accompaniments are manifest, silent, or relapsing-it may lead on to chronic atrophic pyelonephritis and hypertensive renal failure (Rosenheim, 1963). The infection may be symptomless, or nearly so, and evidence from necropsy suggests that by no means all cases are diagnosed before death (Kleeman, Hewitt, and Guze, 1960). Alternatively, symptoms may be ignored or misinterpreted, particularly when they suggest some othér disease, as is so frequent in childhood.

Though repeated urinary infections are, in fact, usually repeated exacerbations of a continuing underlying process (Deluca, Fisher, and Swenson, 1963), even when this process is suspected, the diagnosis can be difficult to confirm. Now that we have a fuller understanding of its potential seriousness, it is very important not to overlook this infection. The prospects of cure have not in the past been very good (Macaulay and Sutton, 1957 ; Straffon and Engel, 1960), but are getting better as we become aware of correctable surgical lesions that are frequently present at the same time, such as vesico-ureteric reflux (Williams and Sturdy, 1961; Gross, Randolph, and Wise, 1963), and now that we possess a new range of antibiotics.

In recent years there has been an increasing inclination to rely for diagnosis upon counts of bacteria and white cells in the urine (Kass, 1960 ; Little, 1962 ; Stansfeld, 1962). In the search for accuracy counting techniques have become more complicated, so that dependence on the laboratory has become greater. We still badly need a reliable and simple test that can disclose urinary infection independently of a laboratory, and which is rapid enough to be used with large numbers of patients (Lancet, 1962). A main aim of the study now to be reported was to determine the efficacy of microscoping unspun urine under standard conditions in the ward or out-patient department as a means of detecting infection of the urinary tract. Its further motive was the wish to discover how many of the children treated for acute urinary infection in a hospital unit during the past 12 years had been rendered permanently free of infection.

\section{Clinical Material and Method}

A letter was written to the parents of 118 children (88 girls and 30 boys) who had been treated for infection of the urinary tract in this hospital group between 1950 and 1962, and who were no longer under hospital surveillance, asking them to bring their children to hospital again for review. Patients with a known malformation of the urinary tract were excluded from the study. Eighty-two children were traced and investigated: 61 were girls and 21 boys. Their ages ranged between 1 and 16 years ; 11 were under the age of 6 , but only two were under 1 year of age.

\footnotetext{
* Paediatric Registrar, South Warwickshire Hospital Group. Present address: The Maternity Hospital, Bristol. + Senior Laboratory Technician, South Warwickshire Hospital Group. ‡ Consultant Paediatrician, South Warwickshire Hospital Group.
}

Each of the 82 children who attended was asked to bring, in a sterile container, an early-morning specimen of urine that had been collected at home, after the genitalia had been washed and dried. At hospital 15 minutes were allocated to each child. Besides history-taking and examination, tests for haemoglobin level, white-cell and differential counts, blood urea, and E.S.R. estimations were arranged, and the urine was examined as follows. Any opalescence that remained in spite of acidification and warming was noted. It was then tested by heating for albumin. Next the urine container was shaken. With a pipette, $0.1 \mathrm{ml}$. urine was placed on a slide, covered with a $1 \times \frac{7}{8}$ in. coverslip and examined under the microscope, first with the low $(\times 100)$ and then with the high power $(\times 450)$. Whether motile bacilli were present or absent was ascertained, and a count was made of all white cells in 20 highpower fields. Calculation shows that if this figure is doubled the approximate number of white cells per c.mm. urine is reached. (See Appendix.) If either the history or the results of examining the urine made the persistence of urinary infection seem likely, then a second urine specimen was obtained in the out-patient department (after perineal cleansing with cetrimide ("cetavlon") $1 / 100$ and was examined at once.

The urines were then sent to the laboratory, where within two hours of the child's interview they were examined once more, this time by a different quantitative method-namely, by counting white cells in two large squares of an improved Neubauer counting chamber and multiplying the result by five to arrive, as before, at the cell count per c.mm. urine (Stansfeld, 1962). The urine was also cultured by plating out one loopful both on blood agar and MacConkey agar. After incubating the cultures at $37^{\circ} \mathrm{C}$. overnight, reports were issued according to the following formula:

$$
\begin{aligned}
& \text { No growth } \quad \ldots \quad \text { Nil. } \\
& \text { Scanty growth } \quad \ldots \quad 1-10 \text { colonies. } \\
& \text { Moderate growth ... More than } 10 \text { colonies but failing } \\
& \text { to cover half the inoculated area. } \\
& \text { Heavy growth } \quad \ldots \quad \text { More than half the inoculated area } \\
& \text { covered by colonies. }
\end{aligned}
$$

When the urine was found to contain more than 10 white cells per c.mm., or to contain a moderate or heavy growth of organisms, persistent urinary infection was suspected, and such children were seen at least once again for further urine examination. Those children in whom pyuria in excess of 10 cells per c.mm. was found more than once, whether or not with clinical evidence of infection, were admitted to hospital for 24 hours, where a catheter specimen of urine was examined, residual urine measured, and intravenous pyelography and cystourethrography performed.

\section{Results}

In accordance with the criterion of Stansfeld (1962), 10 or more polymorphs per c.mm. urine were designated as "significant pyuria." In these children, who were known to have had a previous episode of urinary infection with symptoms, the presence of pyuria at this level in at least two specimens of 
urine and a growth of organisms on culture were regarded as diagnostic of infection of the urinary tract. Data from the survey are shown in Table $I$.

TABLE I.-Sex Incidence and Findings in 82 Children Treated for Acute Urinary Infection Six Months to 13 Years Previously (61 Girls; 21 Boys)

\begin{tabular}{|c|c|c|c|c|c|c|c|c|}
\hline \multicolumn{3}{|c|}{$\begin{array}{c}\text { Group A } \\
\text { Persistent Infection }\end{array}$} & \multicolumn{3}{|c|}{$\begin{array}{c}\text { Group B } \\
\text { "Not Proven " }\end{array}$} & \multicolumn{3}{|c|}{ No Evidence of Infection } \\
\hline Girls & Boys & Total & Girls & Boys & Total & Girls & Boys & Total \\
\hline 19 & 1 & 20 & 17 & 8 & 25 & 25 & 12 & 37 \\
\hline
\end{tabular}

Twenty children (Group A) were shown to have persistent urinary infection. The other 62 children were divided into Groups B and C. Group B was composed of 25 children who remained under suspicion, either by reason of a history of repeated attacks of urinary infection (Table II), or because of other suggestive symptoms (Table III), and yet whose urine

TABLE II.-Further Attacks of Urinary Tract Infection Since Original Illness

\begin{tabular}{ll|c|c|c}
\hline \multirow{2}{*}{ Number of Children } & Group A & Group B & Group C \\
\cline { 2 - 5 } & & 20 & 25 & 37 \\
\hline $\begin{array}{l}\text { One further attack } \\
\text { Two or more attacks }\end{array}$ & $\ldots$ & 8 & 4 & 3 \\
Attack within last three years & $\cdots$ & 9 & 5 & 0 \\
\hline
\end{tabular}

TABLE III.-Symptoms Suggestive of Urinary Infection, as Distributed Among the Three Groups

\begin{tabular}{|c|c|c|c|c|}
\hline \multirow{2}{*}{\multicolumn{2}{|c|}{ Number of Children }} & Group A & Group B & Group C \\
\hline & & 20 & 25 & 37 \\
\hline 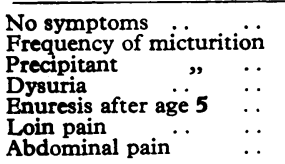 & $\begin{array}{l}\cdots \\
\cdots \\
\cdots \\
\cdots \\
\cdots \\
\cdots\end{array}$ & $\begin{array}{r}11 \\
4 \\
4 \\
5 \\
7 \\
5 \\
1\end{array}$ & $\begin{array}{r}4 \\
8 \\
1 \\
0 \\
16 \\
1 \\
6\end{array}$ & $\begin{array}{r}37 \\
0 \\
0 \\
0 \\
0 \\
0 \\
0\end{array}$ \\
\hline
\end{tabular}

on two successive occasions contained fewer than 10 white-blood cells per c.mm. Also included here are a few children the results of whose urine examination lay just within our accepted range, but which were viewed with a little misgiving-for example, white-cell count 2-9 per c.mm. and a scanty growth of bacteria. Group C consists of 37 children without symptoms suggestive of infection, and with urines within our accepted range (only one specimen was examined, however). In the whole series the ratio of girls to boys was $3: 1$. All but one of the 20 children shown to have persistent urinary infection were girls.

\section{Case History}

The need for Group B is illustrated by the following case history.

Case S.S.-This 7-year-old girl was reviewed as an out-patient in February 1963. She had a past history of two attacks of acute pyelonephritis when aged 4 and 5 . An intravenous pyelogram at the time of the second attack had been reported as normal. She had been enuretic till the age of 5. For the last two years her health had been excellent, except for occasional fevers diagnosed as tonsillitis that were associated with backache. Examination revealed no abnormal physical signs. Her weight was $73 \mathrm{lb} .(33 \mathrm{~kg}$.) and height $4 \mathrm{ft}$. 4 in. $(1.3 \mathrm{~m}$.). Blood-pressure was $110 / 70$; haemoglobin $12 \mathrm{~g} . \%$; white-cell count was normal. E.S.R. Westergren $8 \mathrm{~mm}$. fall in one hour; blood urea was $27 \mathrm{mg} . \%$. The urine contained no albumin or white cells and there was no growth on culture. Her mother was reassured.

In July 1963 she was readmitted to hospital with a history of fever, vomiting, and pain in the left loin for one week. Investigation confirmed the diagnosis of acute pyelonephritis, and also showed the presence of a residual urine of $3 \mathrm{oz}$. $(85 \mathrm{ml}$.) after micturition. Cysto-urethrography demonstrated bilateral ureteric reflux with some degree of hydroureter and hydronephrosis (Fig. 1), as well as a so-called "spin-top deformity" of the upper urethra. Fig. 2 shows a pyelogram taken later on the same day.

In retrospect, it seems certain that this child had a continuous low-grade infection and that the attacks of tonsillitis and backache were, in fact, acute exacerbations. Intermittency of pyuria in patients with this disorder is a well-understood pitfall in diagnosis (Deluca, Fisher, and Swenson, 1963).

Twenty-one children ( $26 \%$ ) gave a history of at least one further attack of urinary-tract infection since the finish of hospital supervision (Table II).

Ninety-seven specimens of urine were examined for pyuria both by wet film (P.M.D.) and Neubauer chamber counts (L.H.). The examinations were made independently, and no attempt to compare the results in detail was made until the end of the survey. The results of the final comparison are summarized in Table IV. On only one occasion was pyuria reported absent by wet-film examination, and subsequently recorded by Neubauer count. On the other hand, significant pyuria was presumably overlooked by the Neubauer count on

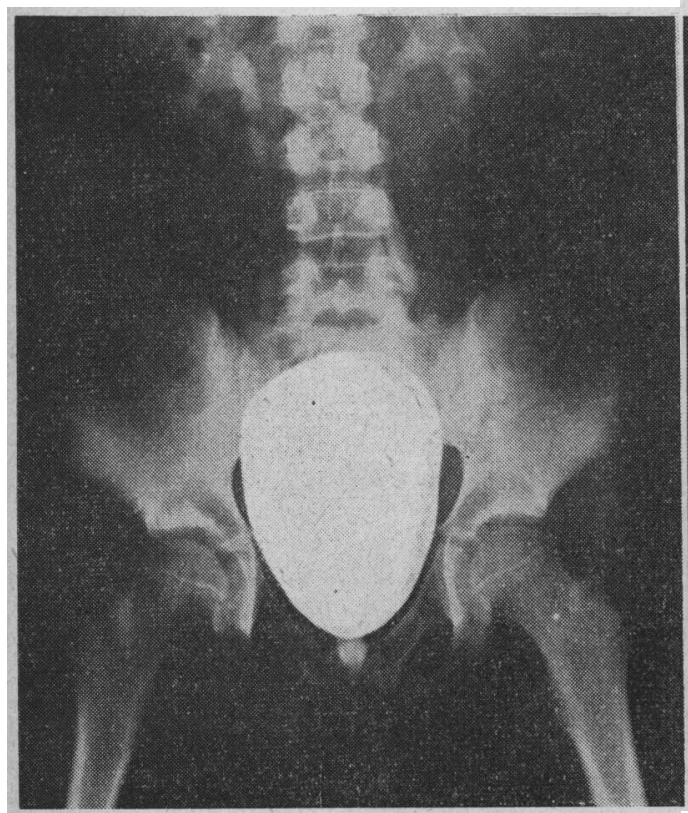

Fig. 1

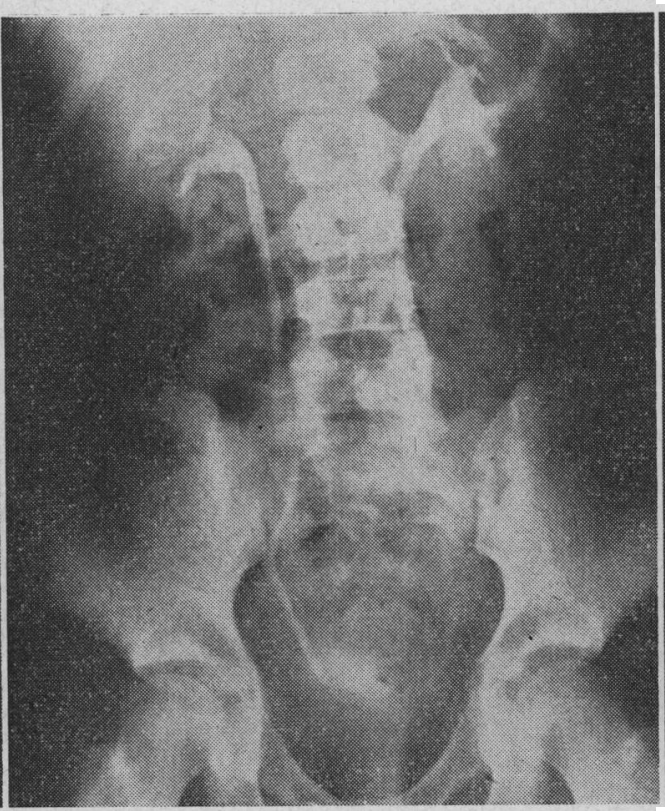

Fig. 2

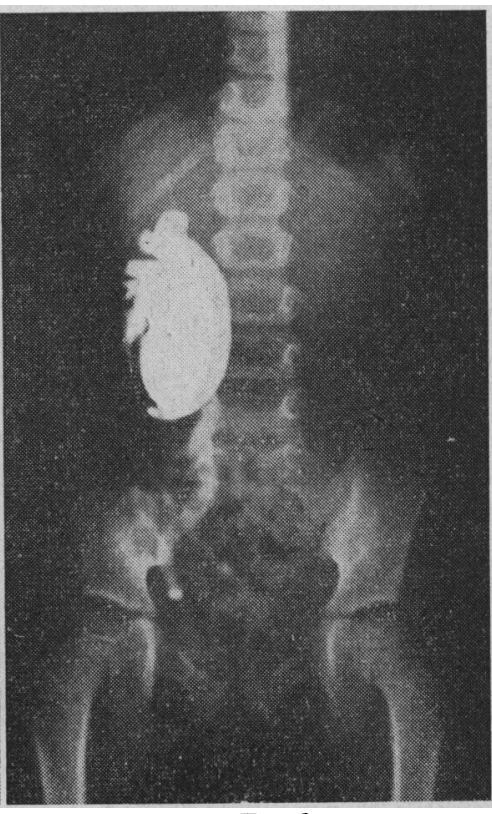

FIg. 3

FIG. 1.-Case S.S. Cysto-urethrogram showing bilateral ureteric reflux. Fig. 2.-Case S. S. Intravenous pyelogram (10 minutes) showing mild degree of hydroureter and hydronephrosis. FIG. 3. - Case J. V. Dilated right renal pelvis and ureter filled during cysto-urethrography. 
one occasion, and on another was incorrectly interpreted as haematuria.

The results of culture of the 82 early-morning specimens of urine brought to out-patients on the first attendance are shown in Table V. Each specimen had been plated out between three and six hours after micturition. In 10 of the 20 Group $A$ children motile bacilli were seen in the wet film examined in out-patients. In each case the organism proved to be Escherichia coli.

The results of routine clinical investigations are listed in Table VI.

TABLE IV.-Comparison of Results of Urine White-cell Counts by Two

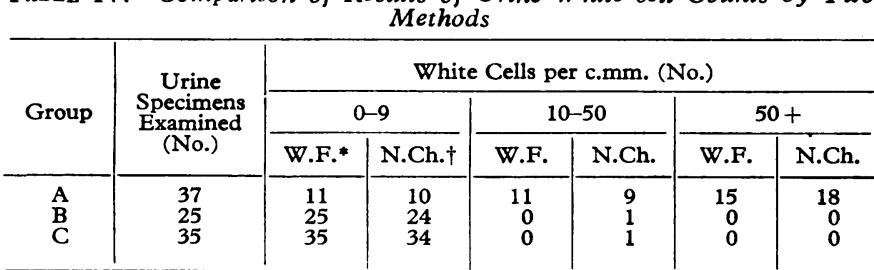

*W.F. = Wet-film count. † N.Ch. = Neubauer chamber count.

TABle V.-Result of Bacteriological Culture of Urines

\begin{tabular}{|c|c|c|c|}
\hline $\begin{array}{l}\text { Result of Culture } \\
\text { (Growth) }\end{array}$ & $\underset{(20)}{\operatorname{Group}} \mathbf{A}$ & $\underset{(25)}{\text { Group B }}$ & $\underset{(37)}{\text { Group }} \mathrm{C}$ \\
\hline $\begin{array}{lll}\text { None } & \ldots & \ldots \\
\text { Scanty } & \ldots & \ldots \\
\text { Moderate } & \ldots \\
\text { Heavy } \quad . & \ldots\end{array}$ & $\begin{array}{r}5 \\
1 \\
4 \\
10\end{array}$ & $\begin{array}{r}19 \\
3 \\
3 \\
0\end{array}$ & $\begin{array}{r}31 \\
4 \\
0 \\
2\end{array}$ \\
\hline
\end{tabular}

TABLE VI.-Additional Routine Observations

\begin{tabular}{|c|c|c|c|}
\hline Investigation & $\underset{(20)}{\text { Group }} \mathbf{A}$ & $\underset{(25)}{\text { Group }}$ B & $\underset{(37)}{\text { Group }} \mathrm{C}$ \\
\hline 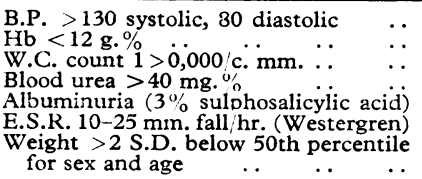 & $\begin{array}{l}2 \\
1 \\
1 \\
2 \\
2 \\
3 \\
0\end{array}$ & $\begin{array}{l}1 \\
6 \\
0 \\
0 \\
1 \\
3 \\
2\end{array}$ & $\begin{array}{l}4 \\
6 \\
2 \\
2 \\
0 \\
4 \\
0\end{array}$ \\
\hline
\end{tabular}

Though in this paper we are not reporting detailed radiographic findings, it must be mentioned that vesico-ureteric reflux was demonstrated in no less than half the children in Group A. This is in conformity with the unpublished results of Smellie, quoted in the Lumleian Lecture for 1963 (Rosenheim, 1963). A remarkable example of this is illustrated in Fig. 3. An intravenous pyelogram on the same child showed striations in the right renal pelvis. We believe that these are folds due to pleating of a voluminous renal pelvis, intermittently overstretched by reflux from the bladder during micturition. This study has also emphasized on several occasions the failure of intravenous pyelography to demonstrate that a ureter and renal pelvis are grossly distended by intermittent reflux.

\section{Discussion}

About a quarter of the 82 children reviewed were found to have persistent infection of the urinary tract, and in about twothirds of these radiography showed some urological abnormality. Nor do we believe that every case of persistent infection in this series has yet been identified; it is clearly still necessary to keep a close watch on children in Group B; while children in Group $\mathrm{C}$ who have had only a single urine examination certainly cannot be regarded as securely screened, however normal they may seem.

Most children had been treated in their first illness by a course of sulphonamide or an antibiotic, but seldom for longer than a week. Surveillance afterwards had in most cases lasted a month. The shortcomings of this form of management are now widely realized (Macaulay and Sutton, 1957 ; Smallpeice, 1958), and leading authorities advocate treatment in terms of months and follow-up in terms of years (Lancet, 1963). The results of this survey certainly confirm the inadequacy of short courses of treatment. Nevertheless, over half the persistently infected children appeared in the best of health, and disclaimed any symptoms. The remainder suffered from a variety of symptoms (Table III) that they had come to accept as normal. It is interesting that nocturnal enuresis after the age of 5 was recorded in $28 \%$ of all children surveyed. The figures of $7 \%$ for girls and $15 \%$ for boys are quoted by Drillien (1961) for enuresis at the age of 5 years in a representative Scottish population of children. This emphasizes the need to dwell on urinary infection as the possible origin of this symptom, before assigning it to other causes.

It is evident that the diagnosis of persistent infection of the urinary tract in children must depend on urine examination. Other investigations (Table VI) were found to be of no assistance. Albuminuria, so of ten relied on to detect infection, was practically valueless. Though for this survey we have only accepted a figure of 10 white cells per c.mm. or more as pathological, we have been impressed by the fact that the majority of normal urines contain fewer than two white cells per c.mm.

The search for pyuria in an early-morning specimen that had been collected at home proved remarkably accurate and rewarding. Twelve specimens of this kind that showed pyuria were compared with "clean" (non-catheter) specimens from the same patients taken up to six hours later in out-patients, and examined immediately. In none was the $\mathrm{pH}$ higher than 8 , and in no case was there any appreciable difference between the two white-cell counts. It was also interesting to find that $80 \%$ of early-morning urines from children apparently without infection gave no growth on culture, and hence a positive culture from a urine obtained under such conditions should not be at once dismissed as due to contamination.

A potential source of error in counting white cells under the microscope comes from the phenomenon of "clumping." This situation can be quickly recognized by the precaution of examining a few low-power fields, when scattered clumps of adherent leucocytes can be readily seen.

While the laboratory worker can direct to the diagnosis of an infected urine more accurate techniques and greater time and experience, the clinician gains from his personal contact with the patient, and knows how and when a certain urine was collected. Moreover, if he examines the urine himself, he obtains a result while other relevant factors are in his mind. The two or three minutes necessary for direct urine examination are in the end a saving of time, as diagnosis and treatment may be accelerated. One observation-namely, that of motile organisms in a freshly obtained urine-is diagnostic, and is usually available only to the clinician. Nevertheless, among the children with persistent urinary infection, one-quarter of their first urine specimens had white-cell counts of less than 10 per c.mm., and a further quarter gave no growth on culture. Thus it is only if they are repeated that these simple tests can be relied on to detect infection. But, with this proviso, they may serve as practical alternatives to the slower and more demanding techniques of white-cell excretion rates and direct bacterial counts (see also Guttmann and Stokes, 1963).

In a recent American survey $1 \%$ of a large group of schoolgirls were found to have persistent urinary infection (Kunin, Zacha, and Paquin, 1962). If this indicates the pattern in Great Britain (and our study suggests that much undiagnosed infection exists), it implies that there are now many thousands of girls in the community with undiagnosed infections of the urinary tract. There are few more obvious challenges facing those concerned with child health, and with the prevention of adult hypertension and renal failure. In the first place, such children must be diagnosed. Using a wet-film technique like the one here described, one person might without difficulty 
screen 100 urines a day. This would make it feasible to test children in large numbers in their schools.

It is hoped that this study shows once more how advantageous it is for a clinician, whether in hospital or in general practice, to examine the urine under a microscope.

\section{Summary}

Eighty-two children who had been treated for acute pyelonephritis during the previous 13 years were reviewed as outpatients.

Twenty children (19 girls) were found to have persistent urinary infection; 11 of these were symptomless and appeared to be in excellent health. Cysto-urethrography showed the presence of vesico-ureteric reflux in half of them.

Independent but parallel white-cell counts were done on 97 specimens of urine in order to compare the value of a standardized wet-film examination in out-patients with the use of a Neubauer counting chamber in the laboratory. Significant pyuria was present in 27 specimens and was detected by the wet-film method in 26 .

The intermittency both of pyuria and bacteriuria (as judged by simple culture) in the urine of children known to have persistent infection was confirmed, and emphasizes the need for more than one examination.

The commonness of this infection, its latency, its possibly serious consequences, and the unsatisfactory results of its treatment present a challenge to paediatricians and others concerned with child health.

We are much indebted for help in this study and in the preparation of this paper to Miss P. Homan, Dr. P. Freeman, Dr. M. Israelski, and the staff of the Radiography Department, Warwick Hospital ; Dr. A. P. Prior and the staff of the Group Pathological
Laboratory ; and Sisters B. E. Morgan and M. D. Lucas, of the Children's Ward, Warwick Hospital.

\section{APPENDIX}

Area of microscope field using $\frac{1}{6}$ th objective and $\times 10$ eyepiece (diameter of field measured with Neubauer counting chamber ruling $=0.4 \mathrm{~mm}$ ).

$$
=\pi \mathrm{r}^{2}=3.14 \times(0.2)^{2}=0.13 \text { sq. } \mathrm{mm} \text {. }
$$

Volume of urine beneath coverslip $=0.1 \mathrm{ml} .=100 \mathrm{c} . \mathrm{mm}$

Area of coverslip used $=22 \mathrm{~mm} . \times 26 \mathrm{~mm} .=572 \mathrm{sq}$. $\mathrm{mm}$.

So depth of urine film on slide $=100 \div 572 \mathrm{~mm} .=0.18 \mathrm{~mm}$.

Therefore volume of urine in each field $=0.13 \times 0.18 \mathrm{c} . \mathrm{mm}$. $=0.025 \mathrm{c} . \mathrm{mm}$. approx.

Hence number of fields per c.mm. $=1 \div 0.025=40$.

The calculations are approximate, as the method is imprecise, but the sum can be adapted to different objectives and sizes of coverslip. Thus it is easy to find roughly the number of high-power fields that must be examined under any specified conditions in order to search 1 c.mm. of urine.

\section{REFERENCES}

Deluca, F. G., Fisher, J. H., and Swenson, O. (1963). New Engl. f. Med., 268, 75

Drillien; C. M. (1961). Arch. Dis. Childh., 36, 515.

Gross, R. E., Randolph, J., and Wise, H. M. (1963). New Engl. F. Med., 268, 5

Guttmann, D., and Stokes, E. J. (1963). Brit. med. F., 1, 1384.

Kass, E. H. (1960). In The Biology of Pyelonephritis, edited by E. L. Quinn and E. H. Kass. Churchill, London.

Kleeman C. R. Hewitt, W. L., and Guze, L. B. (1960). Medicine (Balitimore), 39, 3.

Kunin, C. M., Zacha, E., and Paquin, A. J. (1962). New Engl. F. Med., 266, 1287.

Lancet, $1962,2,598$

1963, 1, 148 .

Little, P. J. (1962). Lancet, 1, 1149.

Macaulay, D., and Sutton, R. N. P. (1957). Ibid., 2, 1318.

Rosenheim, M. L. (1963). Brit. med. F., 1, 1433.

Smallpeice, V. (1958). Lancet, 1, 103.

Stansfeld, J. M. (1962). Arch. Dis. Childh., 37, 257.

Stansfeld, J. M. (1962). Arch. Dis. Childh., 37, 257.

Straffon, R. A., and Engel, W. J. (1960). F. Amer. med. Ass., 174, 1377.
Williams, D. J., and Sturdy, D. E. (1961). Arch. Dis. Childh., 36, 130.

\title{
Urine in Acute and Chronic Renal Failure
}

\author{
M. H. ROSCOE,* PH.D., M.B., CH.B.
}

Brit. med. F., 1964, 1, 1084-1087

Patients with anuria or oliguria often have no previous history of renal disease and nothing to indicate whether they are suffering from an acute and potentially reversible condition or from the final stages of a chronic condition. Attempts have therefore been made in the past, and are repeated here, to see whether when some urine is passed it differs in composition in the acute and chronic diseases.

The chief characteristic investigated was the osmolality, a measure of solute concentration. This was found to be low in both conditions and varied little, so that solute and water output changed together. Some implications of this in the management of acute failure are here considered.

\section{Patients and Methods}

The 10 patients with acute failure are shown in Table I. In eight cases failure was associated with accidents of pregnancy.

^ Department of Medicine, University of Manchester.
The case of phenindione sensitivity has been described in detail elsewhere (Baker and Williams, 1963). In the anuric and oliguric stages the fluid intake was limited to the previous day's loss in urine or vomit plus $400 \mathrm{ml}$., some of this being in the form of sucrose or glucose solution to provide calories. When an adequate urine volume was reached and the blood urea started to fall the diet was increased and free fluid intake allowed. In all cases 24-hour urines were collected.

The eight cases of chronic failure were all in the terminal stages of hypertensive renal failure of varying aetiology. They were given a low-protein diet and free fluid intake. In some cases sodium deficiency was treated by intravenous therapy. Twenty-four-hour urines were collected, except in Cases C2, C3, and C6, where the samples were consecutive one-hour ones.

Osmolalities were estimated by the freezing-point depression, using a Fiske osmometer or calculated from the following formulae :

Urine osmolality $=2\left(\mathrm{Na}++\mathrm{K}++\mathrm{NH}_{4}+\right)+$ urea

Plasma osmolality $=2(\mathrm{Na}++\mathrm{K}+)+$ urea -8 